\title{
Comparison of Parasternal Intercostal Block Using Ropivacaine or bupivacaine for Postoperative Analgesia in Patients Undergoing Cardiac Surgery
}

\author{
Kulbhushan Saini1 ${ }^{*}$, Sandeep Chauhan', Usha Kiran' ${ }^{1}$, Akshay Kumar Bisoi², \\ Minati Choudhury', Suruchi Hasija ${ }^{1}$ \\ ${ }^{1}$ Department of Cardiothoracic and Vascular Anaesthesia, CN Centre, All India Institute of Medical Science, \\ New Delhi, India \\ ${ }^{2}$ M.CH Cardiothoracic and Vascular Surgery, All India Institute of Medical Science, New Delhi, India \\ Email: *kulbhushansaini007@gmail.com, sdeep61@yahoo.com, dr ukiran@yahoo.com, drakbisoi@gmail.com, \\ minatichoudhury2002@yahoo.co.in, suruchi_hasija@hotmail.com
}

Received 1 June 2015; accepted 26 June 2015; published 29 June 2015

Copyright (C) 2015 by authors and Scientific Research Publishing Inc.

This work is licensed under the Creative Commons Attribution International License (CC BY). http://creativecommons.org/licenses/by/4.0/

(c) (i) Open Access

\begin{abstract}
Objective: The objective of this study was to compare the efficacy of $0.5 \%$ ropivacaine and $0.25 \%$ bupivacaine for parasternal intercostal block for postoperative analgesia in children undergoing cardiac surgery. Design: A randomized, controlled, prospective, double blind study. Setting: A tertiary care teaching hospital. Participants: One Hundred children scheduled for cardiac surgery through a median sternotomy were divided into 3 groups of at least 33 children each, receiving either ropivacaine, bupivacaine or saline (control). Interventions: A bilateral parasternal block performed either with $0.5 \%$ ropivacaine or $0.25 \%$ bupiacaine or $0.9 \%$ saline with 5 doses of 0.5 $\mathrm{mL}$ on each side in the $2 \mathrm{nd}$ to 6 th parasternal intercostal spaces 1 to $1.5 \mathrm{~cm}$ lateral to the sternal edge, before sternal wound closure. Measurements and Main Results: The time to extubation was significantly less in children administered the parasternal blocks with ropivacaine or bupivacaine compared to the saline (control) group. The pain scores were lower and comparable in the ropivacaine and bupivacaine groups compared to the saline group. The cumulative fentanyl dose requirement over a 24 -hour period was higher in the saline group than the ropivacaine $(p<0.001)$ and bupivacaine group. No side effects were observed in any of the children. Conclusions: Parasternal blocks either with ropivacaine or bupivacaine appear to be a simple, safe, and useful technique for supplementation of postoperative analgesia in children undergoing cardiac surgery with a median sternotomy.
\end{abstract}

"Corresponding author.

How to cite this paper: Saini, K., Chauhan, S., Kiran, U., Bisoi, A.K., Choudhury, M. and Hasija, S. (2015) Comparison of Parasternal Intercostal Block Using Ropivacaine or bupivacaine for Postoperative Analgesia in Patients Undergoing Cardiac Surgery. World Journal of Cardiovascular Surgery, 5, 49-57. http://dx.doi.org/10.4236/wjcs.2015.56009 


\section{Keywords}

\section{Pediatric Cardiac Patients, Parasternal Intercostalblock, Sternotomy, Ropivacaine, Bupivacaine, Postoperative Pain}

\section{Introduction}

The sternal incision causes intense pain after cardiac surgery [1], and the pain increases during movement [2]. Routine use of low-dose opioid regimens and shorter-acting anesthetic agents facilitate extubation 1 to 6 hours after arrival in the intensive care unit [3]. Early extubation, facilitated by effective postoperative pain control, has potential benefits such as cost containment and rapid recovery. Optimal pain management after cardiac surgery not only improves the comfort and well-being of patients, but more importantly, has physiologic benefits. Appropriate analgesia can reduce pain-related morbidity.

Parenteral opioid analgesics supplemented with nonopioid and nonsteroidal anti-inflammatory analgesics, are the mainstay of alleviating pain after cardiac surgery. The doses of opioids necessary to provide effective pain relief may delay tracheal extubation because of side effects such as respiratory depression, sedation, and gastrointestinal side effects (e.g., nausea, vomiting, and ileus). Epidural analgesia [4] may provide better analgesia, with reduced opioid use, earlier extubation, and improved respiratory function. However, concerns related to systemic hypotension and resulting decreasing coronary perfusion, and also the possibility of a devastating epidural hematoma after aspirin therapy and full heparinization have resulted in regional analgesia not being widely used in cardiac surgical patients [5] [6].

The intercostal nerves innervating the sternum are easily identified at surgery. Infiltration of the parasternal intercostal nerves with local anesthetic agents can be done before sternal wound closure. Studies using parasternal infiltration with local anesthetics as a continuous infusion have shown conflicting results in reducing sternal wound pain and opioid use [7] [8]. One study using parasternal intercostal blocks resulted in a reduction in opioid use and reduction in pain scores [9].

The present study was designed to test the hypothesis that the administration of a parasternal intercostal block using either ropivacaine or bupivaicaine as an adjunct in a multimodal analgesic regimen will provide improved duration opioid-free analgesia in the postoperative period in children undergoing cardiac surgery.

\section{Methods}

After obtaining written informed consent from the parents of 100 participating children, using the sealed envelope method, 100 children undergoing corrective cardiac surgery on CPB were randomized into group R, group $\mathrm{B}$ or group S given either ropivacaine, bupivacaine or saline. The ropivacaine, bupivacaine and saline preparations were prepared in the operating room by a cardiac anesthesiology trainee who was not part of the study. The saline, ropivacaine and bupivacaine solutions looked identical and always remain available in operation theatres. Medication administration and data collection were performed in a double blinded manner such that the patient, the surgeon administering the block, the anesthesiologist providing anesthesia, and the intensive care unit staff giving postoperative care, including the intensivist were not aware of medication assignment.

The components of the parasternal block included anesthetizing the intercostal nerves close to the sternal border, the anterior cutaneous branches of the intercostal nerves. Patients received a parasternal block with $0.5 \%$ ropivacaine, $0.25 \%$ bupiacaine or $0.9 \%$ saline administered in 0.5 - to $2-\mathrm{mL}$ aliquots depending on the weight injected into 5 anterior (2nd-6th) intercostal spaces on each side 1 to $1.5 \mathrm{~cm}$ lateral to the sternal edge. The volume of ropivacaine and bupivacaine in the literature for adult patients for the intercostal block is $4 \mathrm{~mL}$ per intercostal space which is approximately 0.05 to $0.06 \mathrm{~mL} / \mathrm{kg} / \mathrm{space}$ of ropivacaine or bupivacaine. In the present study, a dose of $0.08 \mathrm{~mL} / \mathrm{kg} / \mathrm{space}$ of $0.5 \%$ Ropivacaine and $0.25 \%$ or diluted bupivacine was used. The total dose of was kept well below $5 \mathrm{mg} / \mathrm{kg}$ for ropivacaine and $2 \mathrm{mg} / \mathrm{kg}$ for bupivacaine. The block was administered by the operating surgeon in a standardized fashion before sternal suture placement for sternal wound closure. Care was taken to ensure that there was no blood aspirated to avoid intravascular injection or vascular injury. Patients were observed for 10 minutes for any bleeding caused by an inadvertent vascular injury before the closure of the sternum. 
All patients then were shifted to the intensive care unit (ICU) after the surgery and managed with the institution's ICU protocol for postoperative pain management and ventilation. The postoperative analgesia protocol involves the use of intravenous fentanyl, a 1 to $2 \mu \mathrm{g} / \mathrm{kg}$ bolus as required, in addition to oral acetaminophen, 15 $\mathrm{mg} / \mathrm{kg}$ every 6 hours through the nasogastric tube. Criteria for administering intravenous fentanyl were signs of sympathetic stimulation in the form of undue tachycardia, a rise in mean arterial pressure (rise of $>20 \%$ from the baseline), and a pain score of $>4$, or if the children was in obvious pain and distress at any time point during a subjective assessment by the intensivist. Tracheal extubation was performed when the patient met the following criteria: awake/arousable, hemodynamically stable, no active bleeding, warm peripheries, satisfactory arterial blood gas with an FIO2 < 0.5, no electrolyte abnormalities, minimal inotropic support, or no escalation in inotropic support. The outcome measures of the study were the time to extubation in hours, the postoperative sternal wound pain as judged by the Modified Objective Pain Score3 (MOPS) [10] on a scale of 10 points, and the 24-hour cumulative fentanyl dosage. MOPS is the score used for postoperative pain assessment in children (Table 1). Pain scores were recorded every 2 hours for 24 hours after surgery. Children were observed for any side effects of the parasternal injection in the form of haemodynamic changes, bleeding, haematoma, late problems such as sternal wound infection.

\section{Statistical Analysis}

Continuous variables were compared using repeated measures analysis of variance. For those variables with significant changes, post hoc test with the Bonferroni correction were used to isolate pairwise differences. Fisher's exact test was used for categorical data. Tests were performed using Statistical Analysis System software. Power of the study was $100 \%$ so, this sample size was found to be adequate in each group. Significance was set at a p value $<0.05$.

\begin{tabular}{|c|c|c|}
\hline Criteria & Finding & Points \\
\hline \multirow{3}{*}{ Crying } & None & 0 \\
\hline & Consolable & 1 \\
\hline & Not consolable & 2 \\
\hline \multirow{3}{*}{ Movement } & None & 0 \\
\hline & Restless & 1 \\
\hline & Thrashing & 2 \\
\hline \multirow{4}{*}{ Agitation } & Asleep & 0 \\
\hline & Calm & 0 \\
\hline & Mild & 1 \\
\hline & Hysterical & 2 \\
\hline \multirow{3}{*}{ Posture } & Normal & 0 \\
\hline & Flexed & 1 \\
\hline & Holds injury site & 2 \\
\hline \multirow{4}{*}{ Verbal } & Asleep & 0 \\
\hline & No complaint & 0 \\
\hline & Complains but cannot localize & 1 \\
\hline & Complains and can localize & 2 \\
\hline
\end{tabular}

NOTE. The minimum score was 0 , and the maximum score was 10 . The higher the score, the greater the pain experience for the child. 


\section{Results}

A total of 100 children were randomized (33 bupivacaine, 33 ropivacaine and 34 saline) in the study. The three groups were similar in demographic characteristics (Table 2) including age, weight, body surface area, and other parameters like cardiopulmonary bypass time, aortic cross-clamp time, and intraoperative doses of fentanyl and midazolam. (Table 2)

Table 2 also shows the distribution of congenital cardiac defects in all the three groups for which the surgical procedure was performed. The pain scores (MOPS) over a 24-hour period are depicted in Figure 1 and the trends of measured hemodynamic parameters between the groups are depicted in Figure 2, Figure 3 and Figure 4.

The time to extubation was significantly lower with a mean value of $2.48 \pm 0.42$ hours in bupivacaine group and $2.74 \pm 0.70$ hours in ropivacaine group compared to $5.43 \pm 0.71$ hours in saline group (Table 3 ). This difference was comparable $(\mathrm{p}=0.30)$ in bupivacaine and ropivacaine group but it was statistically significant ( $<<$ $0.001)$ between bupivacaine and saline group. This difference was also statistically significant $(p<0.001)$ between ropivacaine and saline group (Table 3).

The average 24-hour fentanyl administration was significantly lower $1.5 \pm 0.41 \mu \mathrm{g} / \mathrm{kg}$ in bupivacaine group and $1.56 \pm 0.51 \mu \mathrm{g} / \mathrm{kg}$ in ropivacaine group compared to $4.45 \pm 0.56 \mu \mathrm{g} / \mathrm{kg}$ in saline group (Table 3). This difference was also comparable $(\mathrm{p}=1.00)$ in bupivacaine and ropivacaine group but it was statistically significant

Table 2. Demographic data: values expressed as mean standard deviation and numbers.

\begin{tabular}{|c|c|c|c|c|}
\hline Variable & $\begin{array}{l}\text { Bupivacaine Group } \\
\qquad(\mathrm{n}=33)\end{array}$ & $\begin{array}{l}\text { Ropivacaine Group } \\
\qquad(\mathrm{n}=33)\end{array}$ & $\begin{array}{l}\text { Saline Group } \\
\quad(\mathrm{n}=34)\end{array}$ & $\mathrm{p}$ value \\
\hline Age (year) & $4.9 \pm 1.35$ & $4.7 \pm 1.24$ & $4.8 \pm 1.00$ & 0.74 \\
\hline Weight (kg) & $14.27 \pm 2.40$ & $14.18 \pm 2.29$ & $14.8 \pm 2.37$ & 0.51 \\
\hline $\operatorname{BSA}\left(\mathrm{m}^{2}\right)$ & $0.73 \pm 0.02$ & $0.73 \pm 0.02$ & $0.74 \pm 0.02$ & 0.24 \\
\hline Sex $(M / F)$ & $23 / 10$ & $25 / 8$ & $25 / 9$ & $>0.05$ \\
\hline CPB time (min) & $68.33 \pm 2.65$ & $69.09 \pm 3.05$ & $69.87 \pm 2.88$ & 0.09 \\
\hline Aortic cross clamp time (min) & $50.33 \pm 5.90$ & $48.12 \pm 4.54$ & $46.75 \pm 3.01$ & 0.008 \\
\hline $\begin{array}{l}\text { Total intraoperative } \\
\text { fentanyl }(\mu \mathrm{g} / \mathrm{kg})\end{array}$ & $9.53 \pm 0.41$ & $9.53 \pm 0.4$ & $9.46 \pm 0.43$ & 0.79 \\
\hline $\begin{array}{l}\text { Total intraoperative } \\
\text { midazolam (mg/kg) }\end{array}$ & $0.2 \pm 0.01$ & $0.21 \pm 0.01$ & $0.26 \pm 0.01$ & 0.60 \\
\hline \multicolumn{5}{|c|}{ Surgical procedures } \\
\hline ASD closure & 18 & 20 & 22 & \\
\hline VSD closure & 14 & 12 & 12 & \\
\hline DCRV repair & 1 & 1 & & \\
\hline
\end{tabular}

Abbreviations: BSA, body surface area; DCRV, double-chamber right ventricle; ASD, atrial septal defect; VSD, ventricular septal defect.

Table 3. Measured parameters between groups.

\begin{tabular}{|c|c|c|c|c|c|c|}
\hline \multirow[b]{2}{*}{ Variable } & \multirow[b]{2}{*}{$\begin{array}{l}\text { Bupivacaine } \\
\text { Group }(n=33)\end{array}$} & \multirow[b]{2}{*}{$\begin{array}{l}\text { Ropivacaine } \\
\text { Group }(n=33)\end{array}$} & \multirow[b]{2}{*}{$\begin{array}{l}\text { Saline Group } \\
\qquad(\mathrm{n}=34)\end{array}$} & \multicolumn{3}{|c|}{$\mathrm{P}$ values } \\
\hline & & & & $\begin{array}{c}\text { b/w bupivacaine } \\
\text { \& ropivacaine } \\
\text { group }\end{array}$ & $\begin{array}{l}\text { b/w bupivacaine } \\
\text { \& saline group }\end{array}$ & $\begin{array}{l}\text { b/w ropivacaine } \\
\text { \& saline group }\end{array}$ \\
\hline Time to extubation (h) & $2.48 \pm 0.42$ & $2.74 \pm 0.70$ & $5.43 \pm 0.71$ & 0.30 (N S) & $<0.001$ & $<0.001$ \\
\hline $\begin{array}{c}\text { Postoperative Cumulative } \\
\text { fentanyl dose in } 24 \mathrm{~h}(\mu \mathrm{g} / \mathrm{kg})\end{array}$ & $1.5 \pm 0.41$ & $1.56 \pm 0.51$ & $4.45 \pm 0.56$ & 1.00 (N S) & $<0.001$ & $<0.001$ \\
\hline
\end{tabular}

NOTE. Values expressed as mean \pm SD. N S = Not Significant. 
between bupivacaine $\&$ saline group $(\mathrm{p}<0.001)$ and between ropivacaine and saline group $(\mathrm{p}<0.001)$ (Table 3).

The pain score was lower and comparable $(\mathrm{p}>0.05)$ in bupivacaine group and ropivacaine group at all measured time points in intensive care but this score was statistically higher $(\mathrm{p}<0.05)$ in the saline group compared to the two other groups till 18 hours post operatively afterwards scores were comparable, and the difference was not statistically significant (Figure 1).

Hemodynamic data showed that patients were hemodynamic stable in all the three groups. hemodynamics (heart rate, systolic blood pressure and diastolic blood pressure) were comparable in the ropivacaine and bupivacaine groups (Figure 2, Figure 3 and Figure 4) but more tachycardia and hypertension were seen in saline group.

No side effects of the parasternal injection such as bleeding, hematoma or sternal infection were seen in any of the 100 children in the 3 groups.

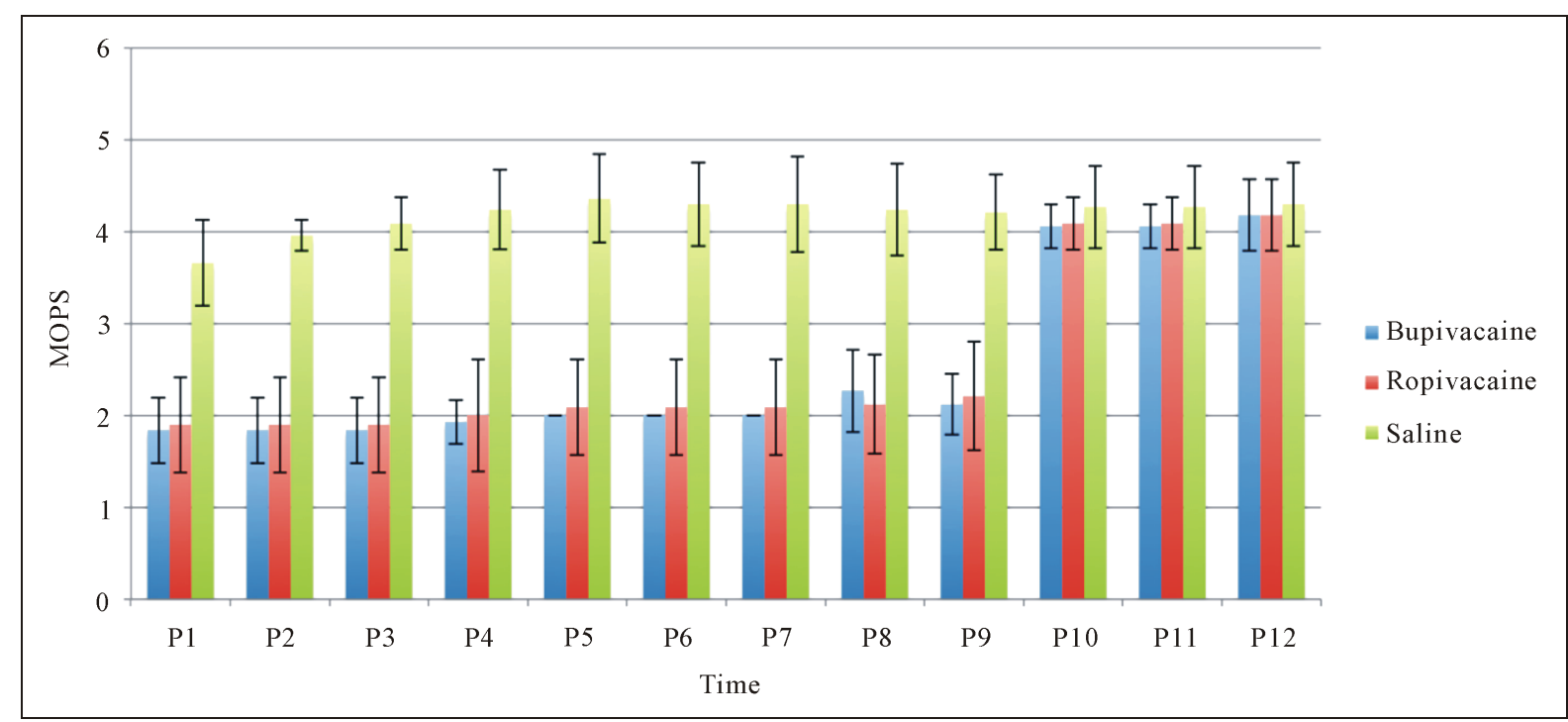

Figure 1. MOPS at different time periods: P1, 2 hours; P2, 4 hours; P3, 6 hours; P4, 8 hours; P5, 10 hours; P6, 12 hours; P7, 14 hours; P8, 16 hours; P9, 18 hours; P10, 20 hours; P11, 22 hours; P12, 24 hours after the block.

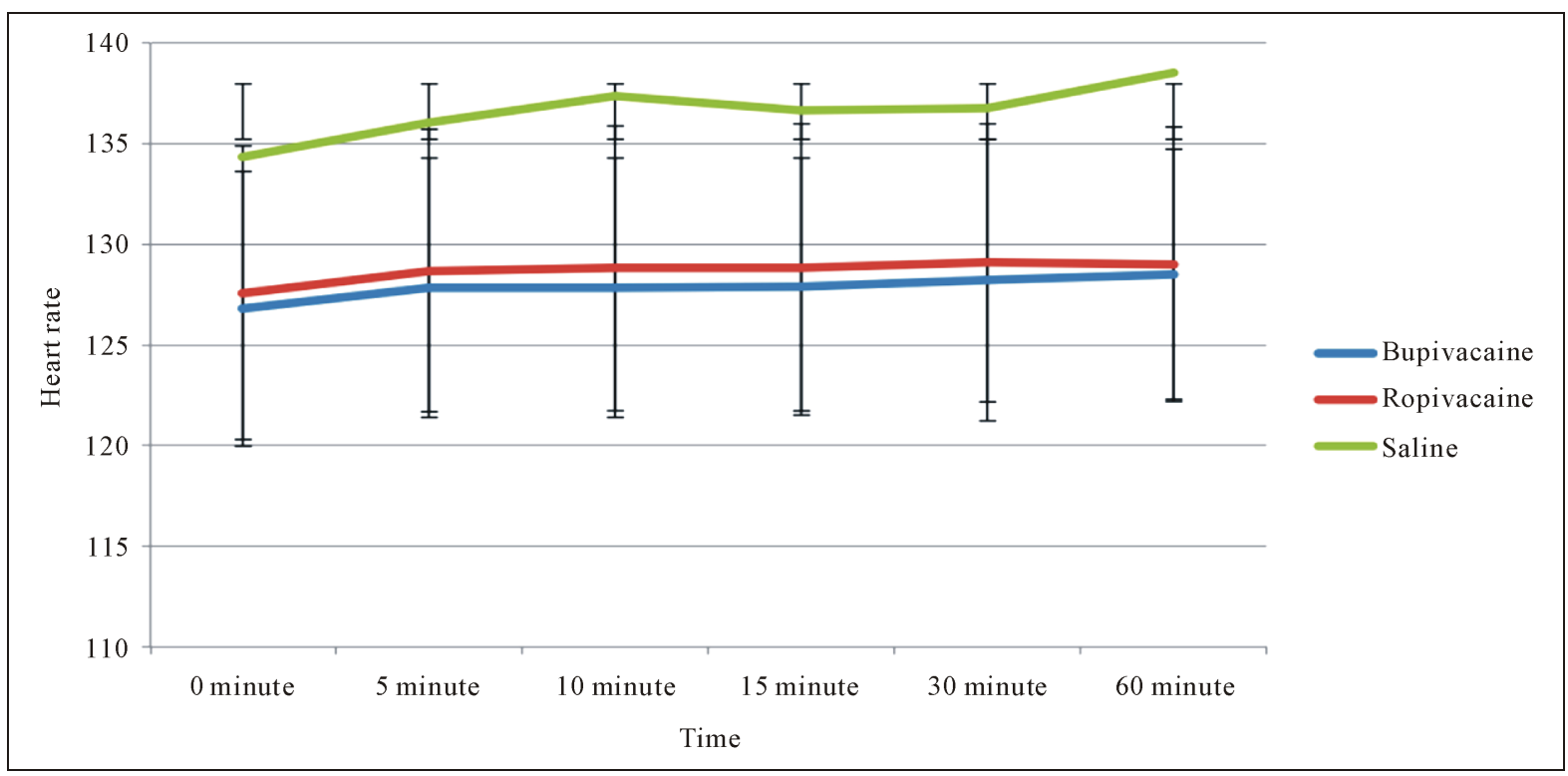

Figure 2. Heart rate with time between three study groups. 


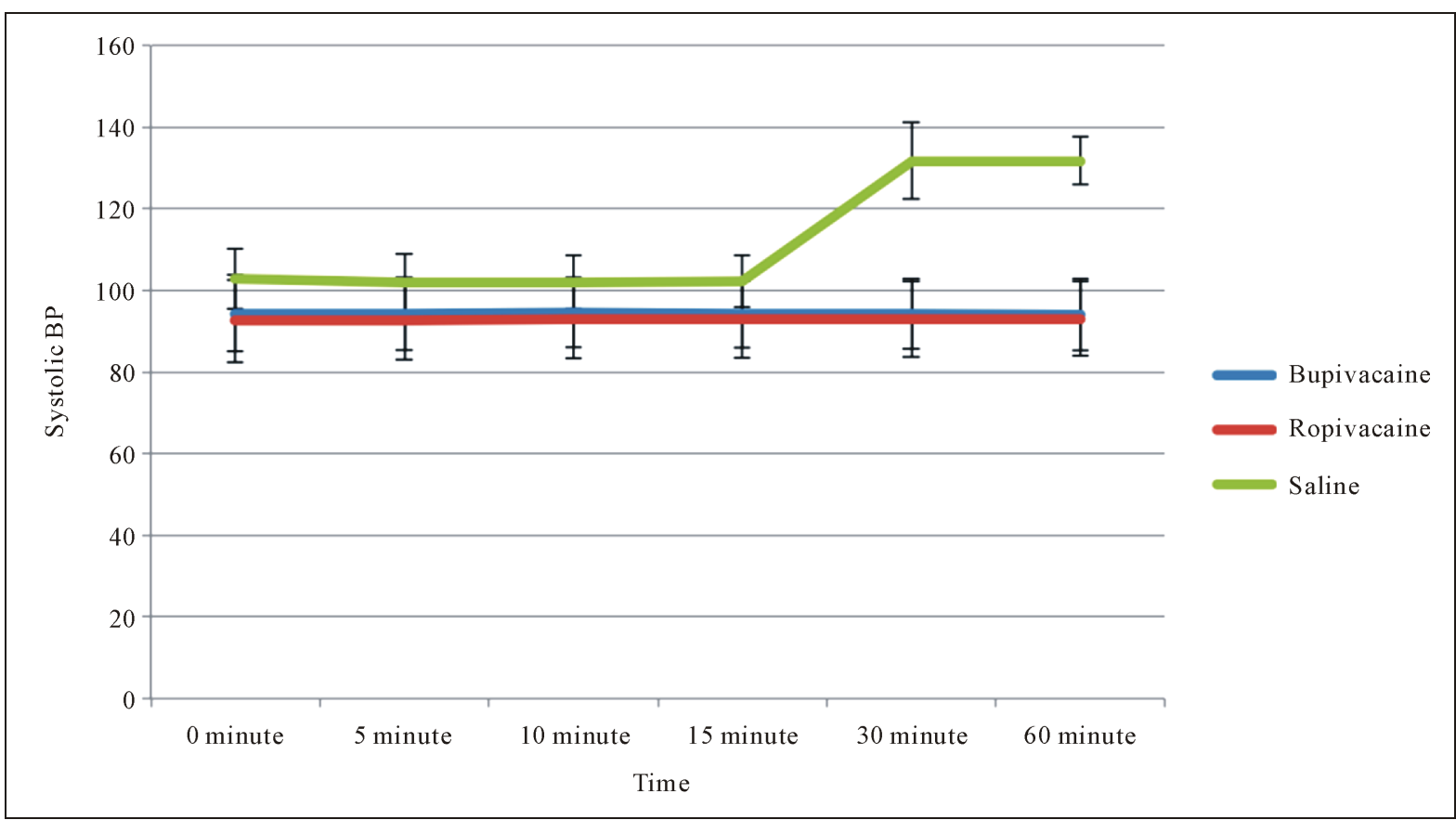

Figure 3. Systolic blood pressure with time between three study groups.

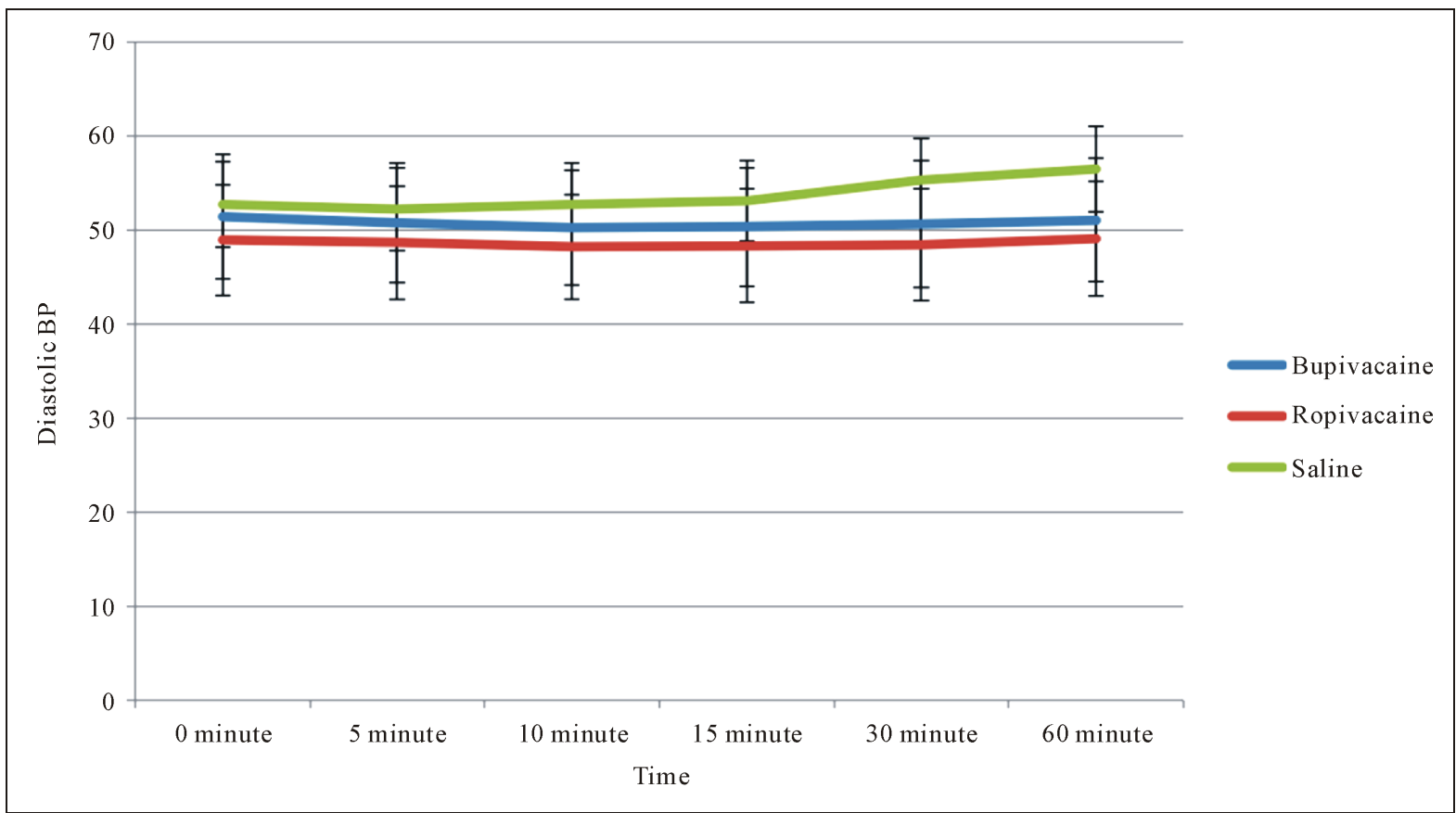

Figure 4. Diastolic blood pressure with time between three study groups.

\section{Discussion}

Early tracheal extubation is a desirable goal for cardiac surgical patients and may lead to better respiratory function and decreased cost and length of ICU stay [11]-[13]. To achieve this goal, the immediate postoperative period is the crucial time to establish stable hemodynamics, alert mental status, and adequate pain control.

Care in the post operative period also includes analgesia for the discomfort related to sternotomy and invasive tubes. Opioids are commonly administered for pain after cardiac surgery but opioids have side effects such as 
sedation, nausea/vomiting, pruritus and constipation. Techniques that allow narcotic sparing may help avoid these side effects and improve overall pain control. Thoracic epidural infusions and intrathecal opioid administration are not without the risks of epidural or intrathecal hemorrhage and subsequent neurologic compromise in the setting of systemic anticoagulation for cardiopulmonary bypass.

Parasternal intercostal blocks may have a role in patients with high narcotic use or in highly selected "fast track" cardiac surgery patients in whom narcotic sparing is desired. This study used MOPS pain scores and postoperative fentanyl requirement to substantiate the effects of each regimen. These variables have been found to correlate fairly well with each other because these parameters indirectly indicate the presence of pain.

Bupivacaine and ropivacaine are long acting local anesthetic agents but ropivacaine, which is a pure S(-) enantiomer, is less cardiac toxic than bupivacaine. Bupivacaine and ropivacaine have already been studied in various regional blockade techniques. In this study, the total dose and concentration of bupivacaine were selected from previous studies [14]-[17], all of which showed the efficacy of plain bupivacaine in concentrations ranging from $0.25 \%$ to $0.5 \%$. Effectiveness of bupivacaine has been shown previously in control of thoracotomy pain [17] [18] but there are no studies to determine recommended concentrations of bupivacaine would provide better pain control in sternotomy pain without toxicity. In this study we used lower concentration $0.25 \%$ of more potent bupivacaine because of great absorption surface from parasternal space.

Because of concerns for systemic accumulation and potential bupivacaine toxicity in cardiac surgical patients, Chaudhary et al. [10] have used ropivacaine for parasternal block in a previous study. Therefore, the only reason to use ropivacaine was the increased margin of safety with ropivacaine [19]. Compared with bupivacaine, at equal milligram doses, ropivacaine [19] is less potent than bupivacaine so a recommended potent concentration of ropivacaine $0.5 \%$ was used in our study. To test the effectiveness of more potent bupivacaine, we have used it in $0.25 \%$ concentration and within the recommended doses, so that the effectiveness of both the drugs can be assessed with minimum volume and concentration. This was also helpful in reducing the chances of cardiovascular and central nervous system toxicity. No toxic complications were seen with bupivacaine and ropivacine in our study.

In this randomized controlled trial both ropivacaine and bupivacaine group received satisfactory analgesia over placebo group, as assessed by pain scores and less required supplementary opioids. The 2 groups had no difference in the requirement for rescue analgesia. The study showed that both local anesthetics significantly reduced postoperative pain and reduced opioid use compared with placebo via parasternal block .The present data add to that of other studies that also have shown the analgesic effects of parasternal intercostal blocks with local anesthetics. McDonald [9] showed that a parasternal intercostal block resulted in a significant reduction in postoperative narcotic use, although there was no significant difference in pain scores. In their study, ropivacaine patients reported attenuation in pain scores during movement from extubation up to 24 hours after surgery.

Studies of continuous local anesthetic infusions into the sternal wound have shown varying results in PCA analgesic dosages. White [8] used a continuous sternal wound infusion of bupivacaine $0.25 \%$ or bupivacaine $0.5 \%$ compared with saline over 48 hours, resulting in no significant differences in dosage of patient-controlled analgesia using morphine. Alternatively, Dowling et al. [7] used a continuous sternal wound infusion of either ropivacaine $0.2 \%$ or saline over 72 hours, resulting in a significantly lower amount of total narcotic analgesia required by the ropivacaine group. McDonald et al. [9] used a parasternal intercostal block of levobupivacaine compared to saline. Patients in the levobupivacaine group used significantly less morphine in the first 4 hours after surgery.

This study showed that the duration of postoperative analgesia in both the local anesthetics groups, with lower pain scores and reduced consumption of supplementary analgesics, extended till 18 hours with single-shot peripheral nerve blocks. 12 these findings are consistent with the study by Althea M [20]. Althea M. Barr [20] showed that ropivacaine parasternal block is an effective treatment for sternal wound pain. It is a safe, simple, and effective adjunct for optimizing of pain control and reducing opioid analgesics after adult cardiac surgery. These data suggest that the parasternal intercostal block with local anesthetics may have a preumptive analgesic effect, preventing establishment of altered central processing of afferent input, which amplifies postoperative pain. The effect of the parasternal block on time to extubation could not be determined in the study by Althea M Barr but our study shows early extubation in both the local anaesthetic group because of effective pain relief without sedation.

Kabukcu $\mathrm{H}$ et al. [21] compared the analgesic efficacy of ropivacaine with bupivacaine in the intercostal nerve block after thoracotomy and concluded that intercostal blockade with bupivacaine provided more signifi- 
cant postoperative analgesia without any effects on hemodynamics and respiratory parameters compared with ropivacaine. Our study dealing with sternotomy pain shows that both bupivacaine and ropivacaine provide similar effective analgesia without any adverse effects on hemodynamics. The reason for this may be that we used lowest effective concentration of potent bupivacaine that provide effective pain relief without any hemodynamic compromise.

Hemodynamic stability is a significant concern in the postoperative management of cardiac surgery patients. Postoperatively, optimal pain relief has been shown to decrease heart rate and blood pressure [22]. Our study showed that children in the saline group experienced hypertension and tachycardia significantly more compared with the ropivacaine and bupivacaine group that can be explained because of inadequate pain control in that group. There was no hypotensive episode after drug administration in any of the children in the three groups. The children were shifted with nitroglycerin and dobutamine infusion in the postoperative intensive care. These infusions were started during rewarming at CPB machine. These infusions were started in all the three groups at the minimum doses thus effects of these drugs will be reflected similarly between groups.

The study demonstrated the utility of a parasternal block as an analgesic adjunct in the postoperative period for having an opioid-sparing effect and facilitating early extubation in children. All the children in this study received intravenous midazolam and fentanyl during the surgery along with sevoflurane for the induction of anesthesia. The quantity of the drugs used was no different in either group on a weight basis in children, thus lessening the residual effect of intraoperative anesthetics as a confounding variable for postoperative analgesia.

In this study, there were no complications related to the parasternal intercostal block. Deep sternal wound infection affecting muscle, bone, and mediastinum did not occur in any of the study patients who were reviewed at 3 weeks after surgery. The parasternal intercostal block was a single-shot injection, thereby avoiding catheter problems encountered in studies using continuous local anesthetic administration. The parasternal block also avoided adverse side effects related to other conventional postoperative analgesia for cardiac surgery patients. Spinal and epidural analgesia are often avoided in the anticoagulated patients because of the catastrophic consequences of neuraxial bleeding and are technically difficult in small children.

\section{Limitations}

Nevertheless, the present study had limitations. We have selected only ASA I and II patients, so efficacy and side effects of the two drugs in high risk patients could not be assessed. The study was also limited by a short duration impairing the ability to assess long-term chest wall pain and length of stay, which may be an area for further research. Irrespective of these potential limitations, the strengths of this study rest in its randomized placebo-controlled design and use of a simple treatment.

\section{Conclusion}

The authors have shown that practically both bupivacaine $0.25 \%$ and ropivacaine $0.5 \%$ with parasternal block are equally effective to control postoperative sternal wound pain after cardiac surgery. A local anesthetic parasternal intercostal block either with bupivacaine or ropivacaine results in less postoperative pain and reduced consumption of opioid and adjunctive analgesia in the general cardiac surgery population.

\section{References}

[1] Ferguson, J., Gilroy, D. and Puntillo, K. (1997) Dimensions of Pain and Analgesic Administration Associated with Coronary Artery Bypass Grafting in an Australian Intensive Care Unit. Journal of Advanced Nursing, 26, 1065-1072. http://dx.doi.org/10.1046/j.1365-2648.1997.00426.x

[2] Nay, P.G., Elliott, S.M. and Harrop-Griffiths, A.W. (1996) Postoperative Pain. Anesthesia, 51, 741-743. http://dx.doi.org/10.1111/j.1365-2044.1996.tb06198.x

[3] Cheng, D.C. (2005) Regional Analgesia and Ultra-Fast-Track Cardiac Anesthesia. Canadian Journal of Anesthesia, 52, 12-17. http://dx.doi.org/10.1007/BF03018574

[4] Desborough, J.P. (1996) Thoracic Epidural Analgesia in Cardiac Surgery. Anesthesia, 51, 805-807. http://dx.doi.org/10.1111/j.1365-2044.1996.tb12604.x

[5] Horlocker, T.T. (1998) Peripheral Nerve Blocks—-Regional Anesthesia for the New Millennium. Regional Anesthesia and Pain Medicine, 23, 237-240. http://dx.doi.org/10.1016/S1098-7339(98)90047-5

[6] Rosen, D.A., Hawkinberry, D.W., Rosen, K.R., et al. (2004) An Epidural Hematoma in an Adolescent Patient after 
Cardiac Surgery. Anesthesia \& Analgesia, 98, 966-969. http://dx.doi.org/10.1213/01.ANE.0000103267.37895.5B

[7] Dowling, R., Thielmeier, K., Ghaly, A., et al. (2003) Improved Pain Control after Cardiac Surgery: Results of a Randomized, Double-Blind, Clinical Trial. The Journal of Thoracic and Cardiovascular Surgery, 126, 1271-1277. http://dx.doi.org/10.1016/S0022-5223(03)00585-3

[8] White, P.F., Rawal, S., Latham, P., et al. (2003) Use of a Continuous Local Anesthetic Infusion for Pain Management after Median Sternotomy. Anesthesiology, 99, 918-923. http://dx.doi.org/10.1097/00000542-200310000-00026

[9] McDonald, S.B., Jacobson, E., Kopacz, D.J., et al. (2005) Parasternal Block and Local Anesthetic Infiltration with Levobupivacaine after Cardiac Surgery with Desflurane: The Effect on Postoperative Pain, Pulmonary Function, and Tracheal Extubation Times. Anesthesia \& Analgesia, 100, 25-32.

http://dx.doi.org/10.1213/01.ANE.0000139652.84897.BD

[10] Chaudhary, V., Chauhan, S., Choudhury, M., Kiran, U., Vasdev, S. and Talwar, S. (2012) Parasternal Intercostal Block with Ropivacaine for Postoperative Analgesia in Pediatric Patients Undergoing Cardiac Surgery: A Double Blind, Randomized, Controlled Study. Journal of Cardiothoracic and Vascular Anesthesia, 26, 439-442. http://dx.doi.org/10.1053/j.jvca.2011.10.012

[11] Lee, T.W. and Jacobson, E. (2000) Pro: Extubation in the Operating Room Should Become the Standard of Care after Cardiac Surgery. Journal of Cardiothoracic and Vascular Anesthesia, 14, 603-609. http://dx.doi.org/10.1053/jcan.2000.9498

[12] Cheng, D.C., Karski, J., Peniston, C., et al. (1996) Early Tracheal Extubation after Coronary Artery Bypass Graft Surgery Reduces Costs and Improves Resource Use. A Prospective, Randomized, Controlled Trial. Anesthesiology, 85, 1300-1310. http://dx.doi.org/10.1097/00000542-199612000-00011

[13] Johnson, D., Thompson, D., Mycyk, T., et al. (1997) Respiratory Outcomes with Early Extubation after Coronary Artery Bypass Surgery. Journal of Cardiothoracic and Vascular Anesthesia, 11, 474-480. http://dx.doi.org/10.1016/S1053-0770(97)90058-6

[14] Polley, L.S., Columb, M.O. and Naughton, N.N. (1999) Relative Analgesic Potencies of Ropivacaine and Bupivacaine for Epidural Analgesia in Labor: Implications for Therapeutic Indexes. Anesthesiology, 90, 944-950. http://dx.doi.org/10.1097/00000542-199904000-00003

[15] Dony, P., Dewinde, V., Vanderick, B., et al. (2000) The Comparative Toxicity of Ropivacaine and Bupivacaine at Equipotent Doses in Rats. Anesthesia \& Analgesia, 91, 1489-1492.

http://dx.doi.org/10.1097/00000539-200012000-00036

[16] Richardson, J., Sabanathan, S., Mearns, A.J., et al. (1995) A Prospective, Randomized Comparison of Interpleural and Paravertebral Analgesia in Thoracic Surgery. British Journal of Anaesthesia, 75, 405-408. http://dx.doi.org/10.1093/bja/75.4.405

[17] Richardson, J., Sabanathan, S., Jones, J., et al. (1999) A Prospective, Randomized Comparison of Preoperative and Continuous Balanced Epidural or Paravertebral Bupivacaine on Post-Thoracotomy Pain, Pulmonary Function and Stress Responses. British Journal of Anaesthesia, 83, 387-392. http://dx.doi.org/10.1093/bja/83.3.387

[18] Marta, G.N., Ignacio, G., Luis, O., Jose María P.-P., Maria, T., Gemma, M.-R. and Leticia, G.-C. (2006) Paravertebral Ropivacaine, 0.3\%, and Bupivacaine, 0.25\%, Provide Similar Pain Relief After Thoracotomy. Journal of Cardiothoracic and Vascular Anesthesia, 20, 644-647. http://dx.doi.org/10.1053/j.jvca.2006.02.032

[19] McClellan, K.J. and Faulds, D. (2000) Ropivacaine: An Update of Its Use in Regional Anaesthesia. Drugs, 60, 1065-1093. http://dx.doi.org/10.2165/00003495-200060050-00007

[20] Althea, M.B., Tutungi, E. and Aubrey, A.A. (2007) Parasternal Intercostal Block with Ropivacaine for Pain Management after Cardiac Surgery: A Double Blind, Randomized, Controlled Trial. Journal of Cardiothoracic and Vascular Anesthesia, 21, 547-553. http://dx.doi.org/10.1053/j.jvca.2006.09.003

[21] Kabukcu, H., Sahin, N., Ertugrul, F., Kanevetci, B.N. and Titiz, T.A. (2004) Comparison the Analgesic Efficacy of Ropivacaine with Bupivacaine in the Intercostal Nerve Block after Thoracotomy: 283. Regional Anesthesia \& Pain Medicine, 29, 68. http://dx.doi.org/10.1097/00115550-200409002-00129

[22] Schwann, N.M. and Chaney, M.A. (2003) No Pain, Much Gain? The Journal of Thoracic and Cardiovascular Surgery, 126, 1261-1264. http://dx.doi.org/10.1016/S0022-5223(03)01327-8 